\title{
Optimizing urban irrigation schemes for the trade-off between energy and water consumption
}

Jiachuan Yang ${ }^{a}$, Zhi-Hua Wang ${ }^{a 1}$

${ }^{a}$ School of Sustainable Engineering and the Built Environment, Arizona State University, PO Box

873005, Tempe, AZ, USA, 85287-3005

\footnotetext{
${ }^{1}$ Corresponding author. Email: zhwang@asu.edu; Tel: +1-480-727-2933; Fax: +1-480-965-0577
} 


\begin{abstract}
Irrigation of green spaces in cities helps to reduce thermal stress and building energy consumption in hot seasons, but requires an intricate balance between energy and water resource usage. While the objective for agricultural irrigation is focused on the yield of produces, urban irrigation needs a new paradigm. In this study, a cutting-edge urban canopy model is applied to assess the impact of a variety of uncontrolled and controlled irrigation schemes for Phoenix. Results show that by increasing surface moisture availability for evapotranspiration, urban irrigation has a cooling effect on the built environment throughout the year. Maximum reduction in canyon air temperature can be more than $3{ }^{\circ} \mathrm{C}$ in summer as compared to the condition without irrigation. Among all investigated schemes, the soil-temperature-controlled irrigation is the most efficient in reducing the annual building energy consumption and the total cost. The total annual saving depends on the controlling soil temperature for irrigation activation, and can be up to about $\$ 1.19$ per square meter wall area as compared to the current irrigation practice. In addition, the scheme can substantially enhance outdoor thermal comfort of pedestrians in summers.
\end{abstract}

Keywords: Building energy efficiency; Energy-water trade-off; Environmental sustainability; Urban canopy model; Urban irrigation 


\section{Introduction}

From 1984 to 2004, global energy use has been growing at an average annual rate of $2 \%$, with the developing countries experiencing higher increasing rates [1]. At present, urban areas account for $67-76 \%$ of global energy use [2], with the percentages expected to increase under future urban expansion. Within the cities, buildings are the dominant energy consumers. Around $40 \%$ of the total final energy consumption in the United States and the European Union is in the building sector $[3,4]$. In recent years there has been a growing concern about the energy consumption as it is the largest contributor to global $\mathrm{CO}_{2}$ emissions, which is the leading cause of climate change [2]. To reduce greenhouse gas emissions and to slow down the depletion of non-renewable energy resources, a number of studies and initiatives have been carried out during the past decades to cut back building energy consumption, including usage of reflective materials [5], deployment of green roofs [6], introducing new building design requirements [7], and improving operation efficiency of building services [8].

While numerous means for reducing building energy consumption have been investigated, the impact of various urban irrigation schemes on building energy efficiency has been less explored. Building energy consumption in cities is closely related to environmental temperatures [9], on which irrigation has cooling effects by increasing the supply of surface moisture for evapotranspiration. Irrigation-induced cooling on near-surface temperature over agricultural land has been extensively documented in both observational [10] and modeling [11,12] studies. In summers, daily maximum air temperature over $100 \%$ irrigated area can be $5{ }^{\circ} \mathrm{C}$ cooler than that over non-irrigated area in California [12]. On the other hand, though the importance of irrigation 
in modeling urban energy and water budget has been recognized $[13,14]$, the explicit impact of irrigation on urban environmental temperature and building energy consumption has rarely been studied. Irrigation of private gardens consumes $16-34 \%$ of the total water supplied to an urban area, let alone the water used for irrigating large open space such as public parks and golf courses [15]. For residential areas within the city of Los Angeles, nearly $225 \times 10^{6} \mathrm{~m}^{3}$ of water was used for irrigation per year [16]. Such amount of irrigation can increase evapotranspiration and cool the urban environment considerably, leading to significantly lower cooling load, especially in densely built areas.

Under the challenge of future climate change, water becomes a more precious resource in cities [17]. Current irrigation practices in most cities are scheduled between sunset and sunrise in order to avoid rapid moisture loss. However, from an energy saving perspective, irrigation should be conducted during daytime as evaporative cooling is driven by available solar radiation at the surface. In this case, irrigating urban vegetation leads to improved building energy efficiency, albeit the trade-off and balance between water and energy resources need to be carefully measured. Different from agricultural irrigation whose objective is mainly on the yield of produces [18], urban irrigation apparently needs a new paradigm by considering the environmental sustainability of cities (e.g. mitigate urban heat islands and save building energy consumption).

It is therefore imperative to understand the relationship between water and energy consumption in the urban environment to develop an optimal urban irrigation scheme. In this study a state-of-the-art urban canopy model is employed [19-21], with realistic representation of 
urban hydrological processes, to identify the environmental impact of urban irrigation in the Phoenix metropolitan area. A variety of uncontrolled and controlled irrigation schemes is investigated, including (1) daily constant scheme, (2) soil-moisture-controlled scheme, and (3) soil-temperature-controlled scheme. Considering the seasonal variation of meteorological conditions and irrigation demands, the net saving of individual scheme is quantified at an annual scale. The trade-off between water and energy consumption are addressed by adopting the combined monetary saving as a measure of environmental co-benefit. The indirect benefit of irrigation on outdoor thermal comfort of pedestrians is also discussed.

\section{Numerical Simulations}

\subsection{Irrigation schemes}

Here the Phoenix metropolitan area is selected as the study area. The simulation period was one entire calendar year, 2012. Phoenix has a population of more than 1.5 million in 2013 , and is the sixth most populous city in the United States [22]. Located in a semi-arid environment, Phoenix has a tremendous demand for cooling compared to other cities [23], thus providing a large potential for building energy saving through optimizing irrigation schemes [24]. In Phoenix, xeric and mesic are two typical vegetated residential landscapes. Xeric sites usually comprise drip-irrigated, low water-use native and/or desert-adapted plants, while mesic sites mainly consist of turf grass and shade trees [25]. Though xeric landscaping helps to conserve water resource, mesic landscaping provides valuable environmental services by, e.g. reducing urban warming and improving stormwater management, and is aesthetically appealing [26]. 
A schematic of irrigation in the urban canopy layer is shown in Fig. 1. Focusing on irrigation of mesic neighborhoods, four different urban irrigation schemes are tested for Phoenix. Scheme 1 is the baseline case with no irrigation during the entire simulation period. Scheme 2 is a daily constant scheme that represents current irrigation practice over mesic residential landscapes in Phoenix. Daily irrigation amount is estimated by dividing monthly irrigation data from an in-situ measurement by the number of days in each month [27]. Following a previous study, irrigation is scheduled at $8 \mathrm{pm}$ local time every day in this scheme [28]. Sensitivity analysis finds that the irrigation time at night has limited impacts on model results. Scheme 3 is a soil-moisture-controlled scheme proposed as a potential urban irrigation paradigm. The idea is to maintain soil moisture at a certain level to keep evaporative cooling effective all the time. Whenever the moisture content of top soil layer $\left(\theta_{\text {top }}\right)$ drops below a critical value, irrigation is carried out to increase the moisture. The amount of irrigation each time is set to be the same as that in the daily constant scheme. Scheme 4 is similar to the soil-moisture-controlled scheme but uses the soil temperature as the controlling variable. Targeted on reducing urban environmental temperature during hot periods, the scheme activates urban irrigation once the temperature of top soil layer exceeds a threshold value. Each time the irrigation amount also equals to the daily irrigation amount of scheme 2. During prolonged daytime period of hot summers, this scheme may easily lead to over irrigation. To avoid waste of water resource, the irrigation amount is then regulated by either the daily irrigation amount of scheme 2 or the difference between $\theta_{\text {top }}$ and saturated soil moisture, whichever is smaller. For cool to cold months where soil temperature is 
consistently lower than the threshold value, essential irrigation is conducted to maintain soil moisture above the wilting point to support biological functions of mesic vegetation.

Volo et al. [29] has conducted a comparative analysis of the impact of irrigation scheduling at both mesic and xeric sites in Phoenix. Typical wilting point for mesic site is found to be from 0.15 to 0.24 . In this study, the lower bound value 0.15 is used as the wilting point and the upper bound value 0.24 is used as the controlling moisture for the soil-moisture-controlled irrigation scheme. Residual and saturated soil moisture is set to be 0.10 and 0.50 . With respect to the threshold soil temperature for irrigation activation in the soil-temperature-controlled scheme, a value of $22{ }^{\circ} \mathrm{C}$ is adopted as the first step to illustrate performance of the scheme.

\subsection{Model evaluation}

To quantify the impact of urban irrigation, an integrated modelling framework that physically resolves energy and water transport in the urban environment is needed. Here a stateof-the-art urban canopy model (UCM) developed by Wang et al. [19-21] is used. The model features detailed description of hydrological processes over natural and engineered surfaces, subfacet heterogeneity, and analytical solutions to heat diffusion equations. Capability of the model has been validated by field measurements under different climate conditions [28]. Detailed computational processes of the model can be found in original paper [19-21] thus are not duplicated here. Accuracy of the UCM in capturing the energy and water budgets of Phoenix is crucial to accurately assess the impact of urban irrigation on environmental temperature and building energy consumption. Previous studies have evaluated the performance of the UCM for 
Phoenix during a short summer period [6]. Considering the monthly variation of meteorological conditions and irrigation demands, the UCM is tested with calibrated parameters from previous studies at an annual scale. Half-hourly meteorological forcing is obtained from the eddycovariance tower deployed at Maryvale, West Phoenix. The experiment site has a footprint area of about $1 \mathrm{~km} \times 1 \mathrm{~km}$, of which about $48.4 \%$ is impervious surface, $36.8 \%$ is bare soil, and $14.6 \%$ is vegetation [28]. Local-scale surface energy balance of the area has been measured for the entire calendar year 2012 (see [30] for more details). Daily constant irrigation (i.e. scheme 2) is added into the model to represent practical supply for soil moisture. Comparison of predicted and observed average ground temperature $\left(T_{g}\right)$, canyon air temperature $\left(T_{c a n}\right)$, sensible heat flux $(H)$, and latent heat flux $(L E)$ is shown in Fig. 2. Gaps in data points are due to failure and maintenance of individual sensors. It is clear from the graphs that model predictions agree with observations reasonably well except for $L E$ in certain months. Discrepancy between observed and predicted $L E$ is about $30 \%$ in October and November. This deviation is largely caused by the spatial variability and uncertainty in precipitation and irrigation data. For the entire simulation

period, root mean square errors are $1.39{ }^{\circ} \mathrm{C}, 1.02{ }^{\circ} \mathrm{C}, 12.51 \mathrm{~W} \mathrm{~m}^{-2}$, and $7.36 \mathrm{~W} \mathrm{~m}^{-2}$ for $T_{g}, T_{\text {can }}$, $H$, and $L E$, respectively. The calibrated input parameters are then adopted for subsequent analysis.

\section{Results and Discussion}

\subsection{Comparison between different irrigation schemes}

On the basis of the demonstrated skill of the UCM in reproducing energy and water budgets for Phoenix, a series of simulations is conducted to investigate the effect of various irrigation 
schemes on environmental temperature, building energy consumption, and outdoor thermal comfort at an annual scale. In 2010, vegetative cover of the Phoenix metropolitan area was estimated to be about $12 \%$ [31]. Aiming to create a healthier, more livable and prosperous desert city, the City of Phoenix has initiated a Tree and Shade Master Plan to achieve the recommended average tree coverage of $25 \%$ by American Forest for southwestern cities [31]. Projecting the increase onto residential area, mesic neighborhoods may have a vegetative cover of more than $30 \%$. For subsequent simulations, a combination of $35 \%$ vegetative cover and $65 \%$ impervious surface is used to represent mesic residential landscape in the near future.

Figure 3 shows the temporal distribution of $\theta_{\text {top }}$ and water consumption of all schemes. The annual variability is markedly different for different schemes: for daily constant irrigation scheme, water use pattern roughly follows a bell curve, with the peak consumption in the premonsoon summer, June; the soil-moisture-controlled scheme maintains $\theta_{\text {top }}$ at a relatively constant level, water consumption increases with soil temperature and the trend is similar to that of daily constant scheme. Irrigation of the soil-temperature-controlled scheme has the most drastic seasonal variation, with water use mainly concentrated in the summer owing to elevated temperatures. Peak water consumption in July and August for the soil-temperature-controlled scheme is 4 times more than that of other two schemes. With vastly different profile of $\theta_{\text {top }}$ and water consumption, it is expected that soil-temperature-controlled and soil-moisture-controlled irrigation have significantly different impacts on thermal condition in the urban canyon. First, various irrigation schedules modify surface heating and turbulent mixing in the urban canyon, subsequently changing the heat exchange between wall surface and canyon air. Second, different 
cooling of the ground surface impacts the amount of longwave radiation emitted towards building surface. Detailed results and discussion on the difference in heat transfer are shown in subsequent sections.

\subsubsection{Effect of irrigation schemes on environmental temperatures}

By replenishing soil moisture for evapotranspiration, urban irrigation has direct cooling impacts on the ground temperature. Note that the UCM does not dynamically simulate the growth and wilt of vegetation. Vegetation is assumed to be fully functional as long as $\theta_{\text {top }}$ is maintained above the wilting point of mesic landscape. Figure 4 demonstrates the reduction of $T_{g}$, $T_{c a n}$, and wall temperature $\left(T_{w}\right)$ by various irrigation schemes as compared to the no-irrigation case. Calculation of these temperatures involves complicated energy and moisture transport in cities due to urban geometry and thermal interaction. Please refer to [20] for detailed computational process. Under the same meteorological condition, evaporative cooling is determined by the volumetric moisture content of top soil layer. Consequently the magnitude of reduction in $T_{g}$ among different schemes (Fig. 4a) follows closely the relative magnitude of $\theta_{\text {top }}$ in Fig. 3a. The soil-moisture-controlled scheme has a larger reduction of $T_{g}$ than other schemes during the winter, whereas the soil-temperature-controlled irrigation induces the greatest cooling in the summer. Maximum monthly reduction in $T_{g}$ is about $2.1{ }^{\circ} \mathrm{C}$ in the winter and about $6.3{ }^{\circ} \mathrm{C}$ in the summer. When moisture content is relatively constant (e.g. the soil-moisture-controlled scheme), evapotranspiration of urban vegetation is regulated by available radiation at the surface, resulting in the larger cooling in summer compared to other seasons. Through the thermal interaction inside the street canyon, urban irrigation has indirect cooling impacts on building 
surface as lower ground temperature reduces thermal radiation emitted towards the wall. Reduced temperatures subsequently weaken the sensible heat flux arising from ground and wall surfaces, leading to the cooling of canyon air. Effect of different irrigation schemes on $T_{c a n}$ and $T_{w}$ is plotted in Figs. $4 \mathrm{~b}$ and $4 \mathrm{c}$, respectively. Monthly variation of the reductions in $T_{c a n}$ and $T_{w}$ is nearly identical to that of reduction in $T_{g}$. Maximum monthly cooling in June is less than $4.0^{\circ} \mathrm{C}$ for $T_{c a n}$ and $3.0{ }^{\circ} \mathrm{C}$ for $T_{w}$, which is significantly lower than the direct cooling effect on $T_{g}$. It is noteworthy that the cooler canyon air and wall surface in turn affect the evapotranspiration process of ground vegetation, thus results here represent the effect of urban irrigation in a built environment with interactive exchange of thermal energy.

\subsubsection{Effect of irrigation schemes on building energy consumption}

Figure 4 clearly illustrates that urban irrigation cools the built environment throughout the annual cycle. Reduced environmental temperature can save cooling load of buildings during warm to hot seasons, it nevertheless increases heating demand of buildings in cool to cold seasons. To quantify the net impact of urban irrigation on building energy efficiency, the onedimensional heat conduction equation through walls is solved as

$$
\frac{\partial T(x, t)}{\partial t}=\alpha_{w} \frac{\partial^{2}}{\partial x^{2}} T(x, t)
$$

where $T$ is temperature inside the building envelop as a function of position $x$ and time $t$, and $\alpha=$ $k / \rho c$ is the thermal diffusivity, with $\rho$ the density, $c$ the specific heat, $k$ the thermal conductivity, and the subscript $w$ denoting walls. The heat equation can be solved analytically using Green's function approach [19] using convolution integral. Given the temporal scale of this study 
(annual), and the fact that convolution requires the saving of all temporal history of the thermal field evolution inside the wall (for 1 year) and is not computationally effective, the finite difference method is adopted to solve the heat equation, by discretizing the wall into a finite number of layers. The temperature profile inside the wall in the $i$-th layer at time instant $j$ is solved as

$$
T_{i}^{j}=T_{i}^{j-1}+\alpha_{w} \frac{T_{i+1}^{j-1}-2 T_{i}^{j-1}+T_{i-1}^{j-1}}{(\Delta x)^{2}} \Delta t
$$

where $\Delta x$ and $\Delta t$ are the space and time intervals respectively. This equation is solved with a constant inner wall surface temperature boundary condition.

Building energy consumption mainly consists of thermal, plug, equipment, and lighting loads. This study focuses on the thermal load as a strong function of environmental (outdoor) factors, whereas the rest are relatively independent of outdoor meteorological condition thus their differences due to irrigation schemes are expected to be small. Thermal load is the amount of heating and cooling energy that needs to be added to or removed from the building to maintain thermal comfort and control moisture for occupants. Thermal load of buildings is determined by the combination of external thermal load and internal thermal load. External loads are made up of heat transmitted through the envelope (roof, wall, and ground), solar gain through windows, heat loss/gain through leaks, infiltration and ventilation, while internal loads include heat generated by people, lighting, and equipment. Note that though the UCM is capable of predicting energy and water budgets for outdoor environment, its capability in simulating interior building physics is rather limited. Therefore, several factors are neglected when estimating building 
energy consumption. Firstly, internal thermal load of buildings is neglected. For the studied residential area in Phoenix, single family house is the major building type [30]. Sparsely populated with little activity and energy-intensive equipment, single family house is generally dominated by external thermal loads. Secondly, latent load of buildings is ignored. This assumption is acceptable for Phoenix as latent load constitutes only about $21 \%$ of the annual ventilation load under hot and dry climate [32]. Thirdly, the contribution of heat flux transmitted through roof and ground floor is not accounted for, as pilot analysis indicates that irrigation in the street canyon has limited effects on roof temperature and soil temperature under building ground floor. Fourthly, due to model limitation, windows are not simulated so that subsequent results represent buildings without windows. Lastly, the efficiency of air conditioning system and the variation of the building interior temperature are not considered. Because the efficiency of air conditioning system is always less than unity, actual energy used for heating and cooling would be larger than the heat flux transmitted through building envelope. Based on these assumptions, building energy consumption is estimated as the heat flux transmitted through the wall in this study, given by

$$
Q_{i n}^{j}=\frac{k_{w}\left(T_{i n}^{j}-T_{b}\right)}{d_{i n} / 2}
$$

where $Q_{i n}^{j}$ is the heat flux entering the building via walls at time step $j, d_{i n}$ is the thickness of the innermost (discrete) layer, $T_{i n}^{j}$ is temperature of the innermost layer at the same time calculated using Eq. (3), and $T_{b}$ is the inner wall surface temperature. A positive $Q_{\text {in }}$ indicates a cooling demand of the building, while a negative value means a heating demand. In the UCM, 
heat transfer within building wall is computed using a multi-layer algorithm, which enables capturing evolution of temperature and heat transfer within the wall as compared to a singlelayer algorithm. In this study, a $R 5$ insulation wall sheathing is considered based on Energy Star recommendation and a typical value of $0.9 \mathrm{~W} \mathrm{~m}^{-1} \mathrm{~K}^{-1}$ is used for $k_{w}$. Inner wall surface temperature is assumed to be maintained at $24{ }^{\circ} \mathrm{C}$ by indoor heating, ventilation, and airconditioning (HVAC) systems for the entire simulation period. Figure 5 presents the monthly water consumption, heating penalty (additional building heating demand), and cooling saving (reduced building cooling demand) by different irrigation schemes as compared to the noirrigation case. In cool to cold season (November to March), the soil-moisture-controlled scheme consumes about 0.29 cubic meter water per square meter vegetated ground area for irrigation, notably larger than $0.22 \mathrm{~m}^{3} \mathrm{~m}^{-2}$ in daily constant scheme and $0.16 \mathrm{~m}^{3} \mathrm{~m}^{-2}$ in the soiltemperature-controlled irrigation. Relatively high moisture level maintained by the soil-moisturecontrolled scheme significantly increases the heating demand of buildings. Monthly maximum penalty can be up to about $6.3 \mathrm{kWh} \mathrm{m}^{-2}$ in early spring and the annual heating penalty is more than $45 \mathrm{kWh} \mathrm{m}^{-2}$. On the other hand, with irrigation concentrated in summer, the soiltemperature-controlled scheme has the least heating penalty as well as the largest cooling saving. Total water consumption of the scheme in summer is $1.23 \mathrm{~m}^{3} \mathrm{~m}^{-2}$, which is about tripled compared to the consumption of $0.38 \mathrm{~m}^{3} \mathrm{~m}^{-2}$ in other two schemes. Compared to the control case (no-irrigation), the maximum monthly saving is more than $20 \mathrm{kWh} \mathrm{m}^{-2}$ in June. For the entire simulation period, total heating penalty and cooling saving is about 32 and $116 \mathrm{kWh} \mathrm{m}^{-2}$, respectively. 


\subsubsection{Effect of irrigation schemes on net cost}

The saving of summer cooling load by lawn irrigation is concomitant with the cost of increased water usage: it takes water to cool an arid city. The trade-off between water and energy consumption naturally leads to the classic question of cost-benefit: Is the saving of cooling energy from urban irrigation worth the cost of water resources? Water conservation has been a primary concern in Phoenix as the city receives water from upstream basins and groundwater pumping. Outdoor water use per capita in Phoenix surpasses rates in other cities. A cost-benefit analysis by combing water and energy consumptions can provide a quantitative estimate, serving as a reasonable economic measure of the environmental sustainability of various irrigation schemes. For unit consistency, total cost is given by:

$$
\operatorname{cost}_{\text {total }}=P_{\text {water }}\left(\frac{w}{h}\right) f_{\text {veg }} \sum_{t} W+P_{\text {electricity }} \sum_{t}\left|Q_{\text {in }}\right|
$$

where $P_{\text {water }}$ and $P_{\text {electricity }}$ are the unit prices of water and electricity usage respectively, $w / h$ is ration between ground and wall areas, $f_{\text {veg }}$ is the areal fraction of vegetation over ground surface, and $W$ is the water consumption rate. The absolute value function is used to account for electricity consumption by both cooling and heating demand of the building. Note that water cost has a unit of cubic meter water per square meter vegetated ground area, and is multiplied by the fraction of vegetated ground area to wall surface area $(w / h) f_{\text {veg }}$ for unit conversion. The resulted total cost is in dollar per square meter wall area. Electricity price is obtained from the basic plan of local company Salt River Project (http://www.srpnet.com/prices/home/basicfaq.aspx\#2) and water price is acquired from the city of Phoenix 
(https://www.phoenix.gov/waterservices/customerservices/rateinfo). Table 1 summarizes the electricity and water prices for Phoenix, both prices have a strong seasonal variation with high charges in summer. Note that the Salt River Project also offers a Time-of-Use plan and an EZ-3 plan in which electricity price is higher during on-peak hours. The choice of electricity plans may affect the results of total monetary saving, however, comparison between different plans is beyond the scope of this study.

Monthly saving in total cost of different irrigation schemes as compared to the no-irrigation case is shown in Fig. 6. Results show that during hot seasons, irrigating more water leads to more total saving. Maximum monthly saving can be up to about $\$ 2.5 \mathrm{~m}^{-2}$ in the soil-temperaturecontrolled scheme for June and August. In cool to cold months when heating demand dominates, additional moisture from irrigation results in increased total cost (negative values in Fig. 6). Monthly cost of the soil-moisture-controlled scheme is about $\$ 0.13 \mathrm{~m}^{-2}$ higher than that of the soil-temperature-controlled scheme throughout the winter. Table 2 summarizes the annual water use, electricity consumption, and total cost of all schemes. Among investigated schemes, the soilmoisture-controlled scheme has the largest total cost. Compared to daily constant irrigation, it consumes more water and has higher total cost, primarily due to the increased heating penalty during cool seasons. The soil-temperature-controlled scheme has a significantly larger annual water usage, which is $60 \%$ more than that of other two schemes. However, the cost of water can be offset by the saving in cooling energy. Overall, the soil-temperature-controlled irrigation scheme is the most efficient in reducing annual total cost of mesic neighborhoods. Table 2 shows that saving by the soil-temperature-controlled irrigation is relatively insignificant as compared to 
the total cost of daily constant irrigation. One plausible reason is that the current irrigation practice in Phoenix is well planned as water is a precious resource for the desert city. It is important to keep in mind that the soil-temperature-controlled irrigation is more effective in reducing urban temperatures during the summer than the current irrigation scheme, thus providing benefits of a better living environment to residents, and being more cost-effective. At last, it is worth to point out that results on net cost are achieved based on the assumption and simplification listed in section 3.1.2. Modification of any condition, especially the efficiency of air conditioning system, may revamp the energy-water trade-off and lead to significant variation in efficiencies of investigated irrigation schemes.

\subsubsection{Effect of irrigation schemes on outdoor thermal comfort}

In addition to alleviating environmental temperature and building energy demand, urban irrigation has important implications for thermal comfort of pedestrians in outdoor urban environment. With a large city size, warm and dry climate, and significant amount of clear days, Phoenix is among the hubs of urban heat islands in the United States where people experience intense thermal discomfort during hot days in outdoor or non-air-conditioned indoor environments [33]. The quantification of outdoor thermal comfort in urban areas is complicated, due to many environmental factors, including but not limited to temperature, humidity, wind speed, radiative exposure, and ambient evaporative and sensible fluxes [34]. Evaluation of the outdoor thermal comfort may be performed using various indices. In this study, the Index of Thermal Stress (ITS) developed by Givoni [35] is selected to identify the impact of urban irrigation on outdoor thermal comfort for Phoenix. ITS is a measure of the rate at which the 
human body must give up moisture to the environment in order to maintain thermal equilibrium, defined by

$$
I T S=E \times \exp \left[0.6\left(\frac{E}{E_{\max }}-0.12\right)\right]
$$

where $E$ is the cooling rate produced by sweat which is required for equilibrium, and $E_{\max }$ is the evaporative capacity of the air. $E$ is given by

$$
E=M-W+R_{n}+C
$$

where $M$ is the body's metabolic rate, $W$ is the energy transformed into mechanical work, $R_{n}$ and $C$ are the environmental heat exchanges due to radiation and convection, respectively. Detailed calculation of $E_{\max }, R_{n}$ and $C$ using meteorological variables can be found in [36], where the net metabolic heat gain $(M-W)$ is taken as a constant $70 \mathrm{~W} \mathrm{~m}^{-2}$ for the pedestrian. Pearlmutter et al. [37] has employed the index to assess outdoor thermal comfort condition in urban canyon with different geometries.

The ITS for pedestrians doing gentle outdoor activities (e.g. walking) in the street canyon is calculated. Monthly averaged ITS in different irrigation schemes are summarized in Table 3. Givoni [35] conducted a series of empirical experiments to correlate ITS with subjective thermal sensation. An ITS between 280 and $400 \mathrm{~W} \mathrm{~m}^{-2}$ indicates a "hot" thermal condition and above $400 \mathrm{~W} \mathrm{~m}^{-2}$ is "very hot". Following their definition, outdoor thermal comfort condition will be very hot for pedestrians from April to September in Phoenix. Reduction of ITS by different irrigation schemes as compared to the no-irrigation case is shown in Fig. 7. By reducing environmental temperature and increasing humidity, urban irrigation leads to reduction in ITS 
throughout the year except for September. Due to four major rainfall events, September has a significantly higher relative humidity than other months. Further moisture brought by irrigation under the humid condition thus results in degradation of outdoor thermal comfort. In hot summer, reduction of ITS by the soil-temperature-controlled scheme is more significant than that of other

two schemes. Maximum reduction is about $35 \mathrm{~W} \mathrm{~m}^{-2}$ in June. It is noteworthy that outdoor human thermal comfort is a rather subjective measure that is related to physiological aspects of pedestrians, which can vary from region to region. The results of this study indicate a rather qualitatively positive impact of urban irrigation on outdoor thermal comfort in Phoenix.

\subsection{Optimal soil temperature for the soil-temperature-controlled irrigation}

The comparative analysis in previous section indicates that the soil-temperature-controlled irrigation is the best scheme in terms of annual total saving. The governing mechanism of the scheme is to generate saving in cooling energy in summers as well as to minimize heating penalty during winters. The use of water to cool a city in summers necessarily points to the intricate balance of water-energy nexus. Is there an optimal temperature regulating the soiltemperature-controlled irrigation that can maximize the combined saving of energy and water resources? To address this question, a set of simulations with six controlling top-soil temperatures (in addition to the initial controlling temperature of $22{ }^{\circ} \mathrm{C}$ ) is carried out, namely 20 , $21,23,24,25$, and $26{ }^{\circ} \mathrm{C}$, above which the soil-temperature-controlled irrigation will be activated. 
Figure 8 demonstrates the annual saving in energy, water and the combined cost by different soil-temperature-controlled irrigation schemes as compared to the no-irrigation case. Positive values in the graph denote net saving. At a lower activating temperature, the soil-temperaturecontrolled scheme consumes more water during hot periods. Due to the nonlinear distribution of temperature, cost of water decreases more rapidly at a lower soil temperature. The combined annual saving exhibits a nonlinear trend as a function of activating soil temperature. Water usage with an activating temperature of $26{ }^{\circ} \mathrm{C}$ is only about $18 \%$ of that with an activating temperature

of $20{ }^{\circ} \mathrm{C}$. The latter consumes $17.1 \mathrm{kWh} \mathrm{m}^{-2}$ less energy than the former. Maximum annual saving is about $\$ 9.20$ per square meter wall area at $23{ }^{\circ} \mathrm{C}$, while minimum saving of $\$ 6.47$ per square meter wall area is found with an activating temperature of $20{ }^{\circ} \mathrm{C}$. Comparing with the annual saving of $\$ 8.01 \mathrm{~m}^{-2}$ by daily constant scheme, the activating top-soil temperature needs to be carefully determined in order to yield the optimal irrigation scheme using temperature control in terms of the trade-off between water and energy. It is worth to mention that optimal activating soil temperature depends on meteorological conditions and thus can vary vastly for different seasons or different climatic zones. Analysis here using a yearly constant activating temperature serves as a first step towards optimizing irrigation schemes for building energy efficiency. Further studies on a temporally varying activating soil temperature are needed.

\section{Concluding Remarks}

In this study, an advanced urban canopy model was used to identify the environmental effect of urban irrigation for the Phoenix metropolitan area. The performance of various 
uncontrolled and controlled irrigation schemes on mesic residential landscapes is investigated, including (1) daily constant irrigation, (2) soil-moisture-controlled irrigation, and (3) soiltemperature-controlled irrigation. In general, irrigating mesic landscape in urban areas cools the urban environment via enhanced evapotranspiration. Maximum cooling effect on canyon air temperature can be more than $3{ }^{\circ} \mathrm{C}$ in summer. Results show that the soil-temperature-controlled irrigation can reduce annual building energy consumption and the combined energy-water cost of the no irrigation case by about $6 \%$, which is the most efficient among investigated schemes. By design, the soil-temperature-controlled scheme activates irrigation during hot periods and helps to preserve water during cold seasons, thus optimizes the trade-off between energy and water use. Annual saving can be up to about $\$ 1.19$ per square meter wall area compared to the current irrigation practice (daily constant) in Phoenix. The total saving of the soil-temperature-controlled scheme requires a fine balance in energy-water use. Site-specific analysis is therefore required to determine the optimal activating soil temperatures.

It is noteworthy that estimated saving in this study provides a qualitative rather than quantitative guidance for water-energy trade-off in urban irrigation, due to (i) the simplifications made in estimating the building energy consumption, and (ii) the neglect of the uncertainty inherent in model physics and the parameter space. In addition, modeling results, especially those for the daily constant irrigation scheme, are based on the monthly available in-situ measurement of irrigation over mesic residential landscapes. Timing, duration and amount of actual irrigation vary from neighbour to neighbour thus the results cannot be directly up-scaled to extract monetary saving for the entire city. Having more detailed data availability in other study 
areas will help to validate and improve the proposed irrigation schemes in this study. In addition, the numerical model can be further improved by incorporating dynamic representation of mesic vegetation (e.g., soil water uptake, growth and withering, and root zone dynamics) and advanced simulation of building energy use (e.g., latent load, internal thermal load, and windows). Nevertheless the current study deepens our insight into the trade-off between energy and water use and facilitates a development of new paradigm for urban irrigation.

\section{Acknowledgements}

This work is supported by the National Science Foundation (NSF) under grant number CBET-1435881. Field measurement by the eddy-covariance tower at Maryvale, West Phoenix sponsored by NSF under grant EF-1049251 is acknowledged. 


\section{References}

[1] L. Pérez-Lombard, J. Ortiz, C. Pout, A review on buildings energy consumption information, Energy Buildings, 40 (3) (2008) 394-398.

[2] K. Seto, S. Dhakal, Chapter 12: Human Settlements, Infrastructure, and Spatial Planning, in: Climate Change 2014: Mitigation of Climate Change. Contribution of Working Group III to the Fifth Assessment Report of the Intergovernmental Panel on Climate Change, 2014, pp. 67-76.

[3] R. Retzlaff, Green building assessment systems: A framework and comparison for planners, J. Am. Plan. Assoc., 74 (4) (2008) 505-519.

[4] European Commission, Energy, transport and environment indicators, Eurostat, Italy, 2012, pp. 234.

[5] J. Yang, Z.H. Wang, K.E. Kaloush, Environmental impacts of reflective materials: Is high albedo a 'silver bullet' for mitigating urban heat island?, Renew. Sustain. Energy Rev., 47 (2015) 830-843.

[6] J. Yang, Z.H. Wang, Physical parameterization and sensitivity of urban hydrological models: Application to green roof systems, Build. Environ., 75 (2014) 250-263.

[7] Y. Feng, Thermal design standards for energy efficiency of residential buildings in hot summer/cold winter zones, Energy Buildings, 36 (12) (2004) 1309-1312.

[8] C. Thormark, A low energy building in a life cycle - its embodied energy, energy need for operation and recycling potential, Build. Environ., 37 (4) (2002) 429-435.

[9] H. Akbari, Cooling our communities. A guidebook on tree planting and light-colored surfacing, Lawrence Berkeley National Laboratory, 2009, pp. 245.

[10] W.J. Sacks, B.I. Cook, N. Buenning, S. Levis, J.H. Helkowski, Effects of global irrigation 
on the near-surface climate, Clim. Dyn., 33 (2-3) (2009) 159-175.

[11] C. Bonfils, D. Lobell, Empirical evidence for a recent slowdown in irrigation-induced cooling, Proc. Natl. Acad. Sci. USA, 104 (34) (2007) 13582-13587.

[12] D.B. Lobell, C. Bonfils, The effect of irrigation on regional temperatures: A spatial and temporal analysis of trends in California, 1934-2002, J. Clim., 21 (10) (2008) 2063-2071.

[13] V. Mitchell, H. Cleugh, C. Grimmond, J. Xu, Linking urban water balance and energy balance models to analyse urban design options, Hydrol. Process., 22 (16) (2008) 28912900.

[14] P. Vahmani, T.S. Hogue, Incorporating an urban irrigation module into the Noah land surface model coupled with an urban canopy model, J. Hydrometeorol., 15 (2014) 14401456.

[15] V. Mitchell, R.G. Mein, T.A. McMahon, Modelling the urban water cycle, Environ. Modell. Softw., 16 (7) (2001) 615-629.

[16] LADWP (City of Los Angeles Department of Water and Power), Urban water management plan: fiscal year 2000-2001 annual update, City of Los Angeles, California, 2001.

[17] K. Vairavamoorthy, S.D. Gorantiwar, A. Pathirana, Managing urban water supplies in developing countries - Climate change and water scarcity scenarios, Phys. Chem. Earth, 33 (5) (2008) 330-339.

[18] R. Topak, S. Suheri, B. Acar, Comparison of energy of irrigation regimes in sugar beet production in a semi-arid region, Energy, 35 (12) (2010) 5464-5471.

[19] Z.H. Wang, E. Bou-Zeid, J.A. Smith, A spatially-analytical scheme for surface temperatures and conductive heat fluxes in urban canopy models, Boundary-Layer Meteorol., 138 (2) (2011) 171-193. 
[20] Z.H. Wang, E. Bou-Zeid, J.A. Smith, A coupled energy transport and hydrological model for urban canopies evaluated using a wireless sensor network, Q. J. R. Meteorol. Soc., 139 (675) (2013) 1643-1657.

[21] Z.H. Wang, Monte Carlo simulations of radiative heat exchange in a street canyon with trees, Sol. Energy, 110 (2014) 704-713.

[22] United States Census Bureau, Phoenix quick facts, in: http://quickfacts.census.gov/qfd/states/04/0455000.html, Retrieved November 23, 2014.

[23] M. Sivak, Where to live in the United States: Combined energy demand for heating and cooling in the 50 largest metropolitan areas, Cities, 25 (6) (2008) 396-398.

[24] P. Gober, A. Brazel, R. Quay, S. Myint, S. Grossman-Clarke, A. Miller, S. Rossi, Using watered landscapes to manipulate urban heat island effects: How much water will it take to cool Phoenix?, J. Am. Plan. Assoc., 76 (1) (2010) 109-121.

[25] A. Middel, K. Häb, A.J. Brazel, C.A. Martin, S. Guhathakurta, Impact of urban form and design on mid-afternoon microclimate in Phoenix Local Climate Zones, Landscape Urban Plan., 122 (2014) 16-28.

[26] W.T.L. Chow, A.J. Brazel, Assessing xeriscaping as a sustainable heat island mitigation approach for a desert city, Build Environ., 47 (0) (2012) 170-181.

[27] C. Martin, L. Stabler, Plant gas exchange and water status in urban desert landscapes, J. Arid. Environ., 51 (2) (2002) 235-254.

[28] J. Yang, Z.H. Wang, F. Chen, S. Miao, M. Tewari, J. Voogt, S. Myint, Enhancing hydrologic modeling in the coupled Weather Research and Forecasting - urban modeling system, Boundray-Layer Meteorol., 155 (1) (2015) 87-109.

[29] T.J. Volo, E.R. Vivoni, C.A. Martin, S. Earl, B.L. Ruddell, Modeling soil moisture, water 
partitioning and plant water stress under irrigated conditions in desert urban areas, Ecohydrol., 7 (2014) 1297-1313.

[30] W.T. Chow, T.J. Volo, E.R. Vivoni, G.D. Jenerette, B.L. Ruddell, Seasonal dynamics of a suburban energy balance in Phoenix, Arizona, Int. J. Climatol., Published online (2014) DOI:10.1002/joc.3947.

[31] City of Phoenix, Tree and shade master plan, 2010, pp. 53.

[32] L.G. Harriman III, D. Plager, D. Kosar, Dehumidification and cooling loads from ventilation air, ASHRAE J., 39 (11) (1997) 37-45.

[33] A. Brazel, N. Selover, R. Vose, G. Heisler, The tale of two climates - Baltimore and Phoenix urban LTER sites, Clim. Res., 15 (2) (2000) 123-135.

[34] A.K. Mishra, M. Ramgopal, Field studies on human thermal comfort-An overview, Build Environ., 64 (2013) 94-106.

[35] B. Givoni, Estimation of the effect of climate on man: Development of a new thermal index, PhD Thesis, Israel Institute of Technology, 1963.

[36] L. Shashua-Bar, D. Pearlmutter, E. Erell, The influence of trees and grass on outdoor thermal comfort in a hot-arid environment, Int. J. Climatol., 31 (10) (2011) 1498-1506.

[37] D. Pearlmutter, P. Berliner, E. Shaviv, Integrated modeling of pedestrian energy exchange and thermal comfort in urban street canyons, Build Environ., 42 (6) (2007) 2396-2409. 


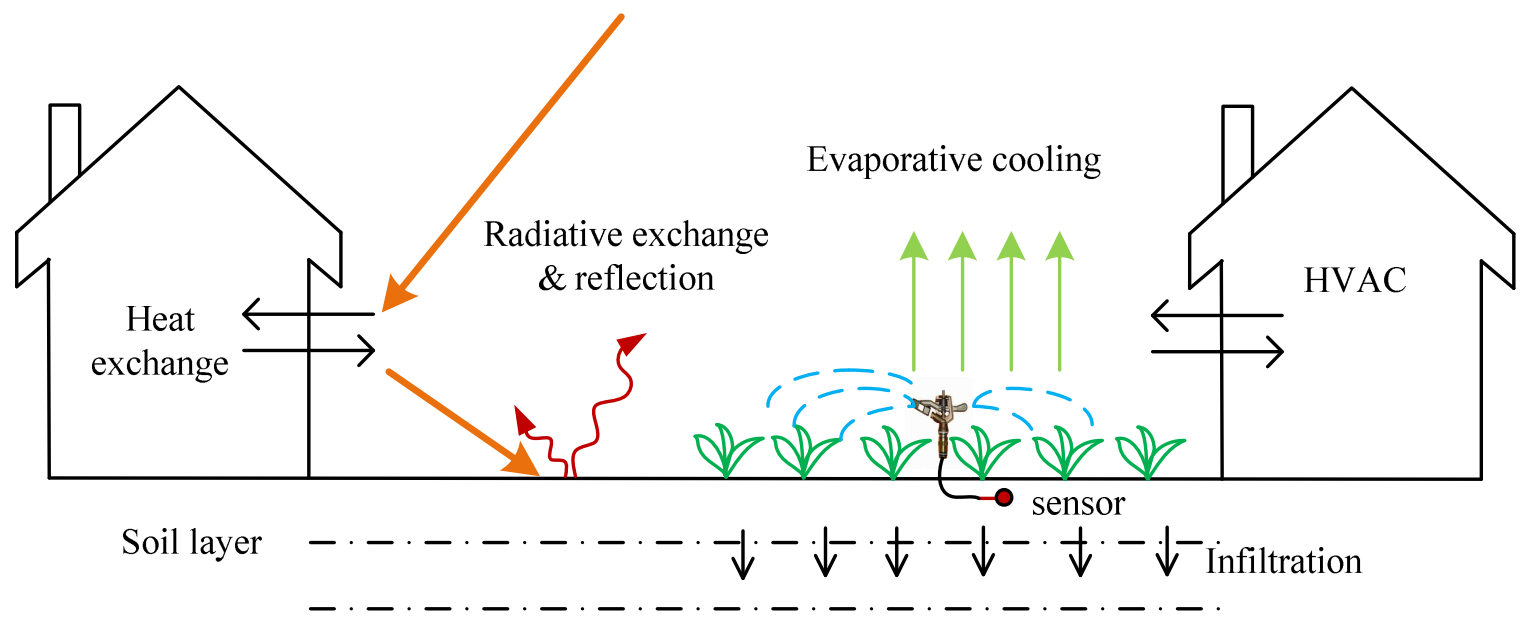

Fig. 1. A schematic of lawn irrigation in residential areas. The two-dimensional "big canyon" representation is adopted to represent the urban area with the longitudinal dimension (canyon length) much larger than the planar dimensions (building height and road width). 
(a)

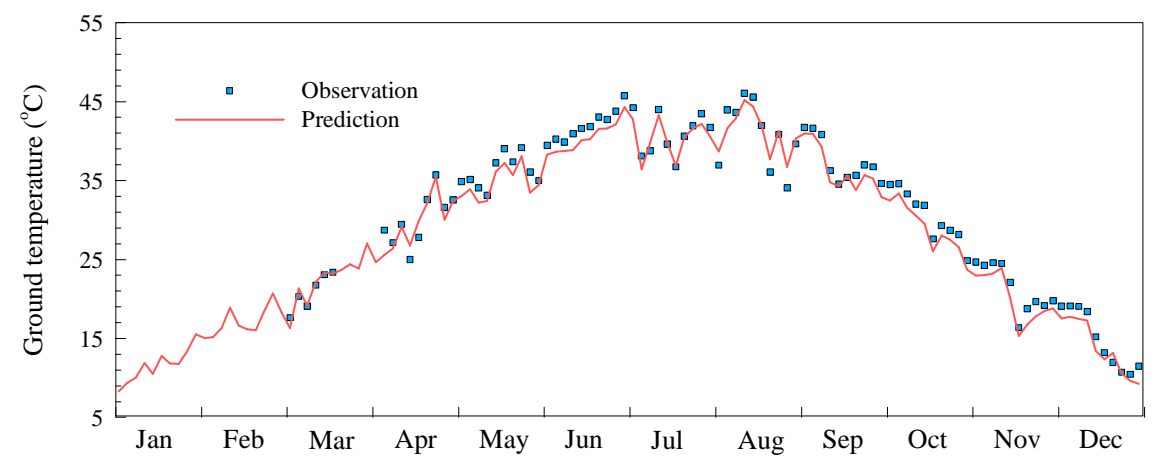

(b)

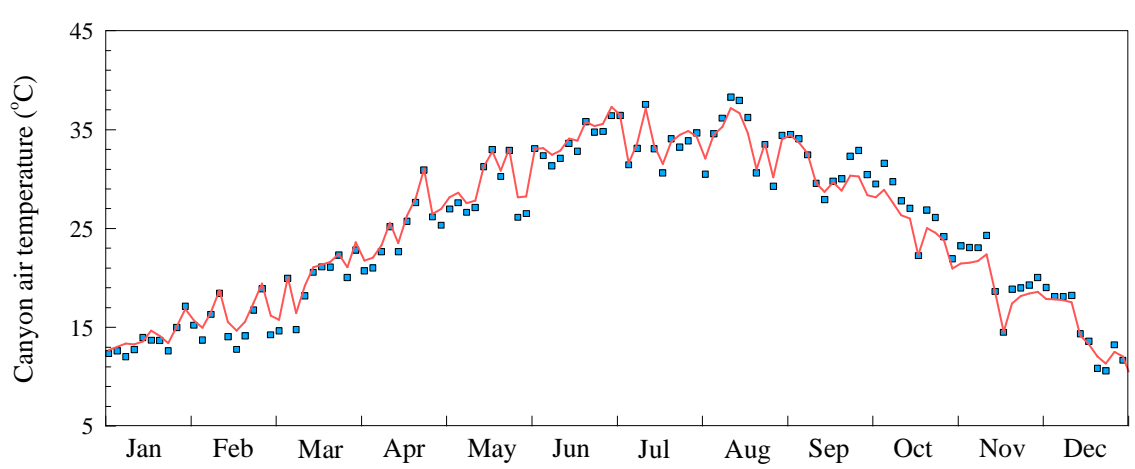

(c)

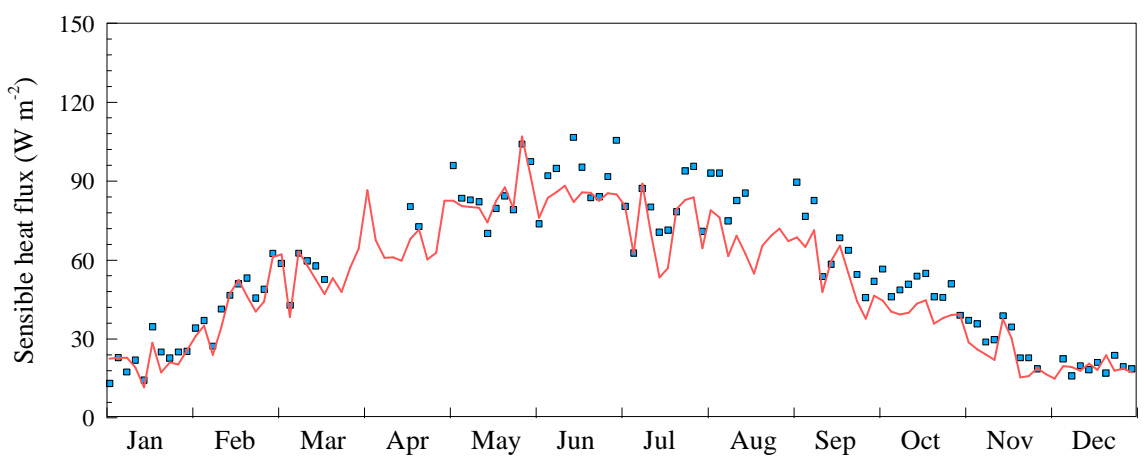

(d)

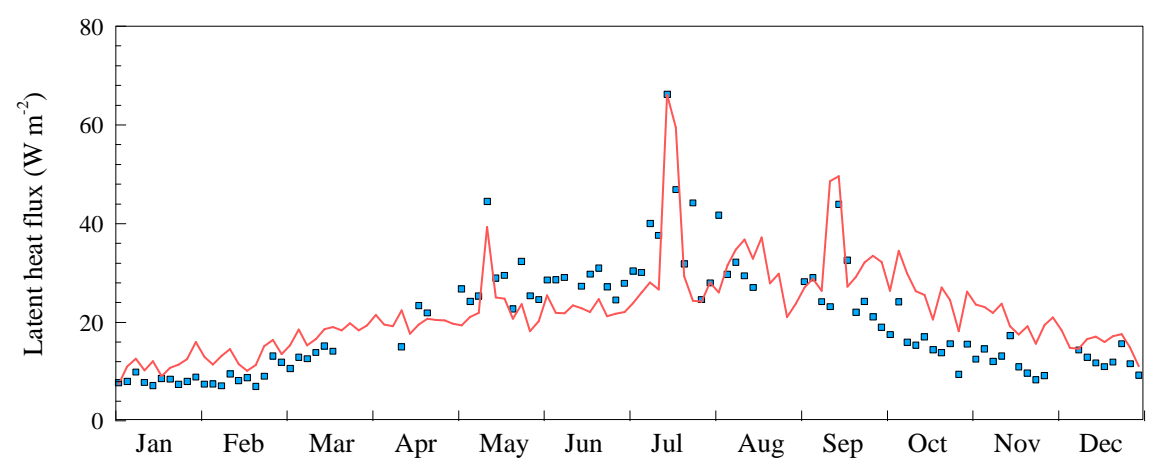

Fig. 2. Comparison of predicted and observed average (a) $T_{g}$, (b) $T_{\text {can }}$, (c) $H$, and (d) $L E$ in Phoenix during the entire simulation period. 
(a)

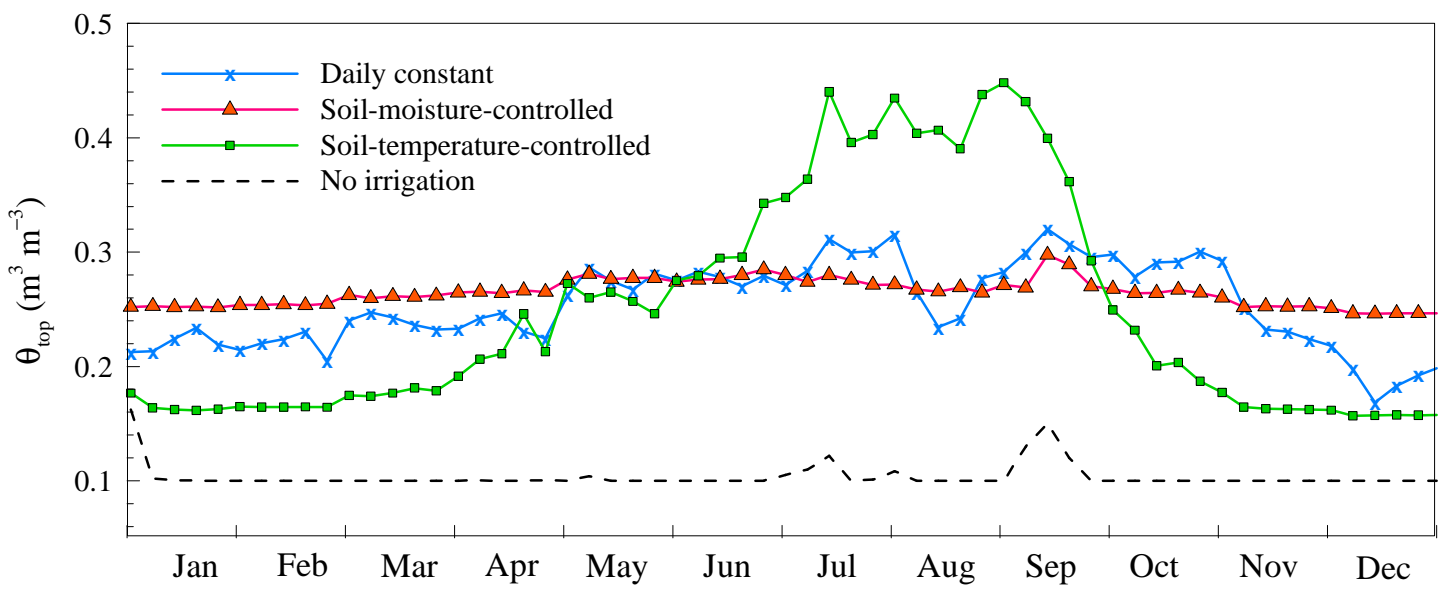

(b)

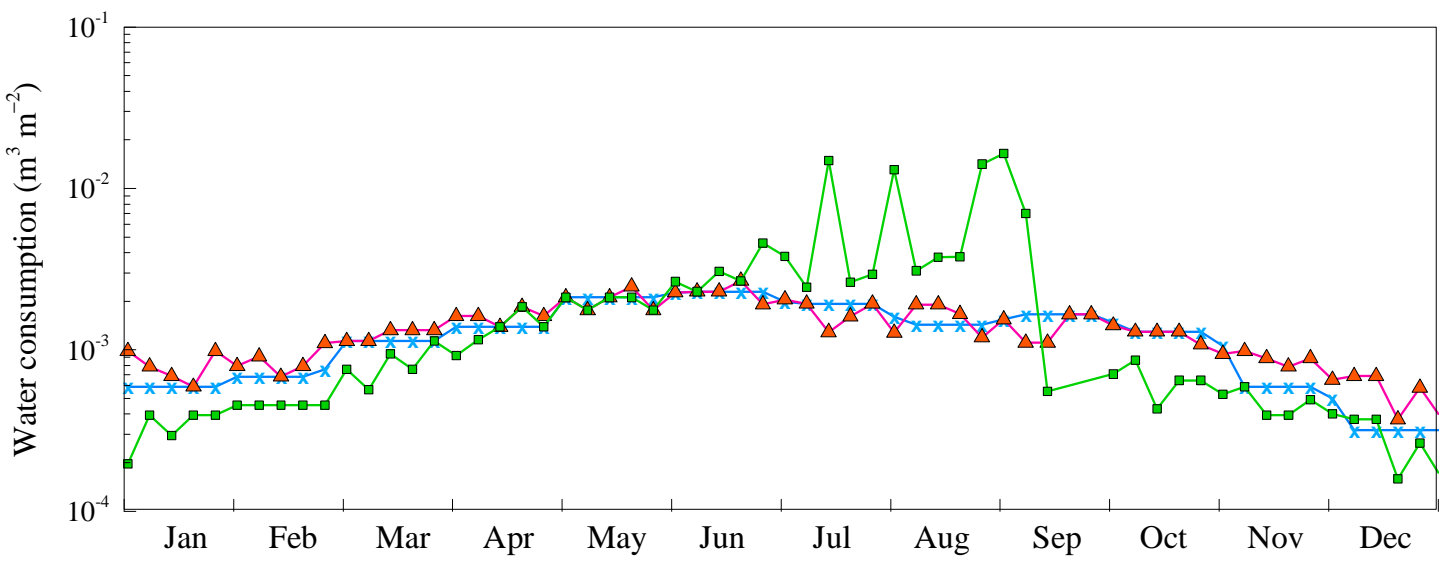

Fig. 3. Simulated temporal distribution of (a) $\theta_{\text {top }}$, and (b) water consumption among different irrigation schemes in Phoenix in 2012. 
(a)

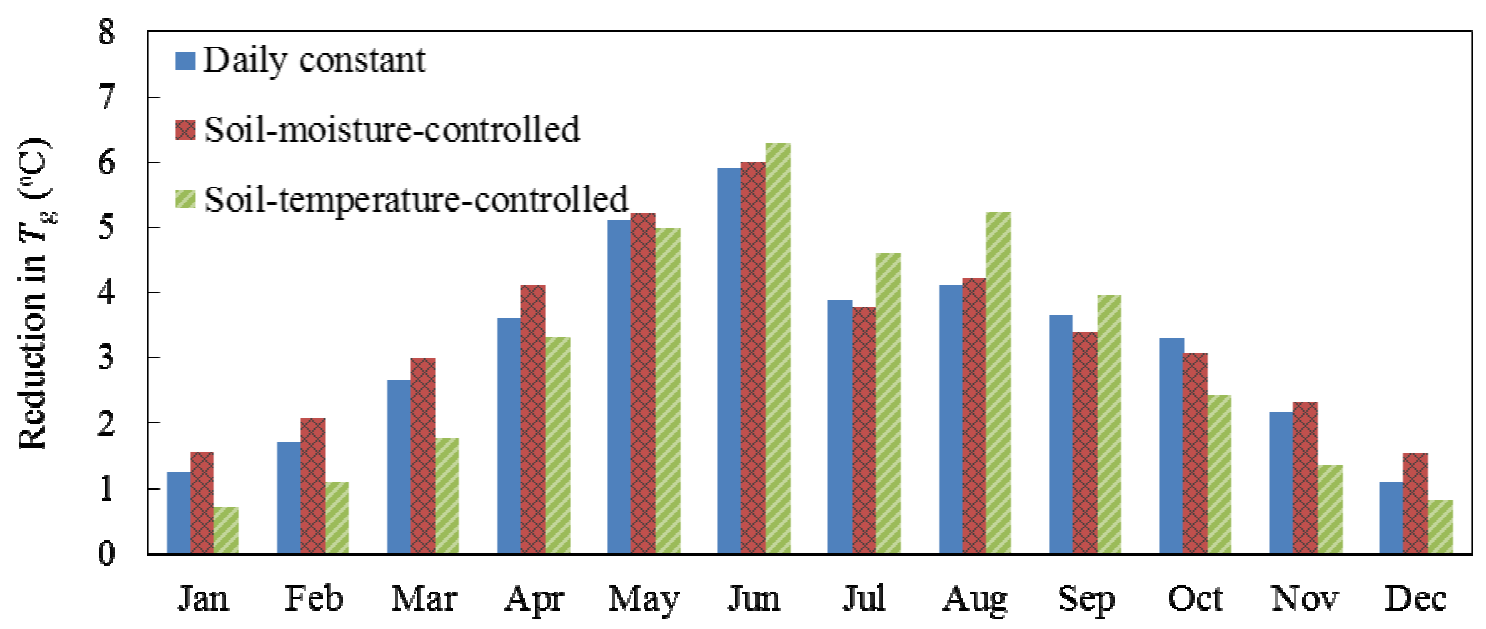

(b)

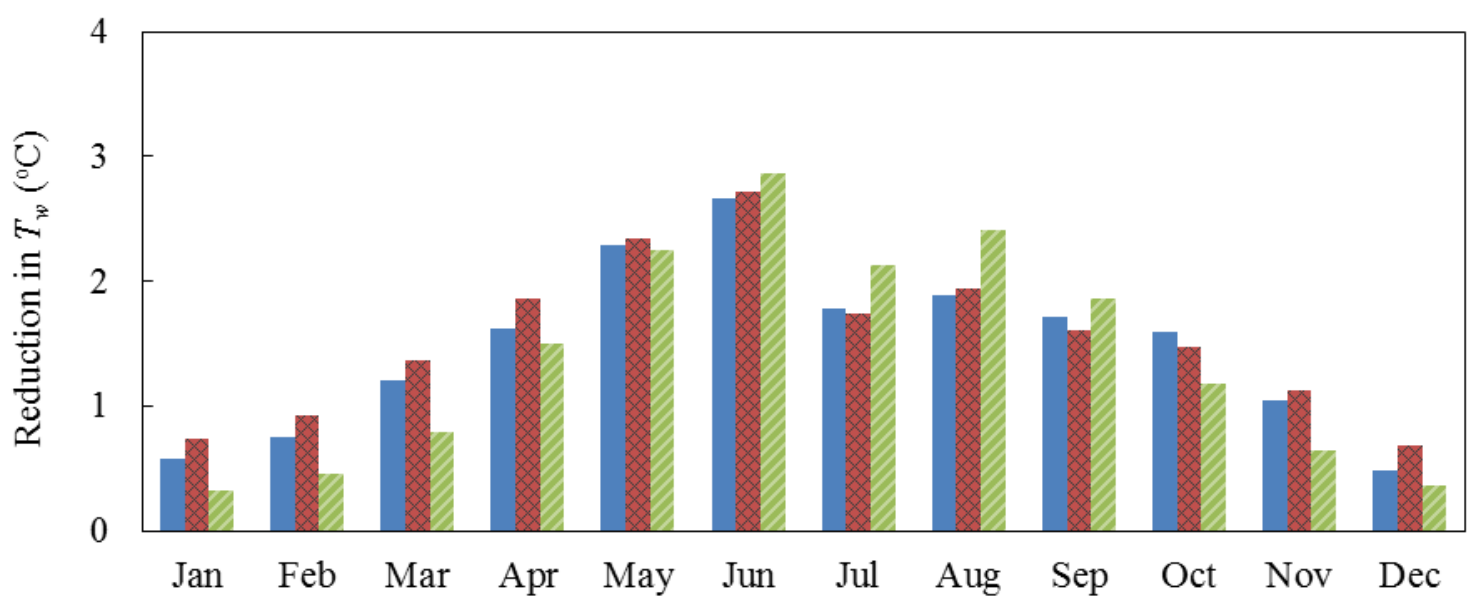

(c)

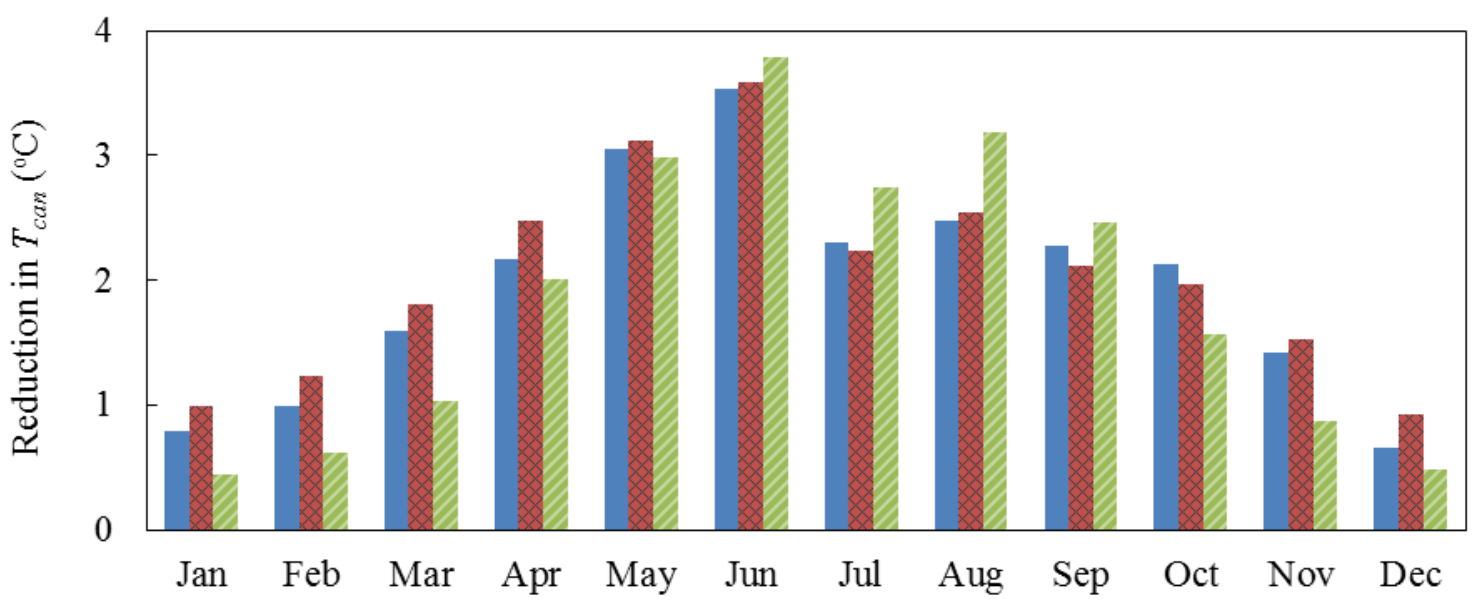

Fig. 4. Monthly reduction in (a) $T_{g}$, (b) $T_{w}$, and (c) $T_{c a n}$ by various irrigation schemes as compared to the baseline (no-irrigation) case. Scale of the vertical axis is different for subplots. 
(a)

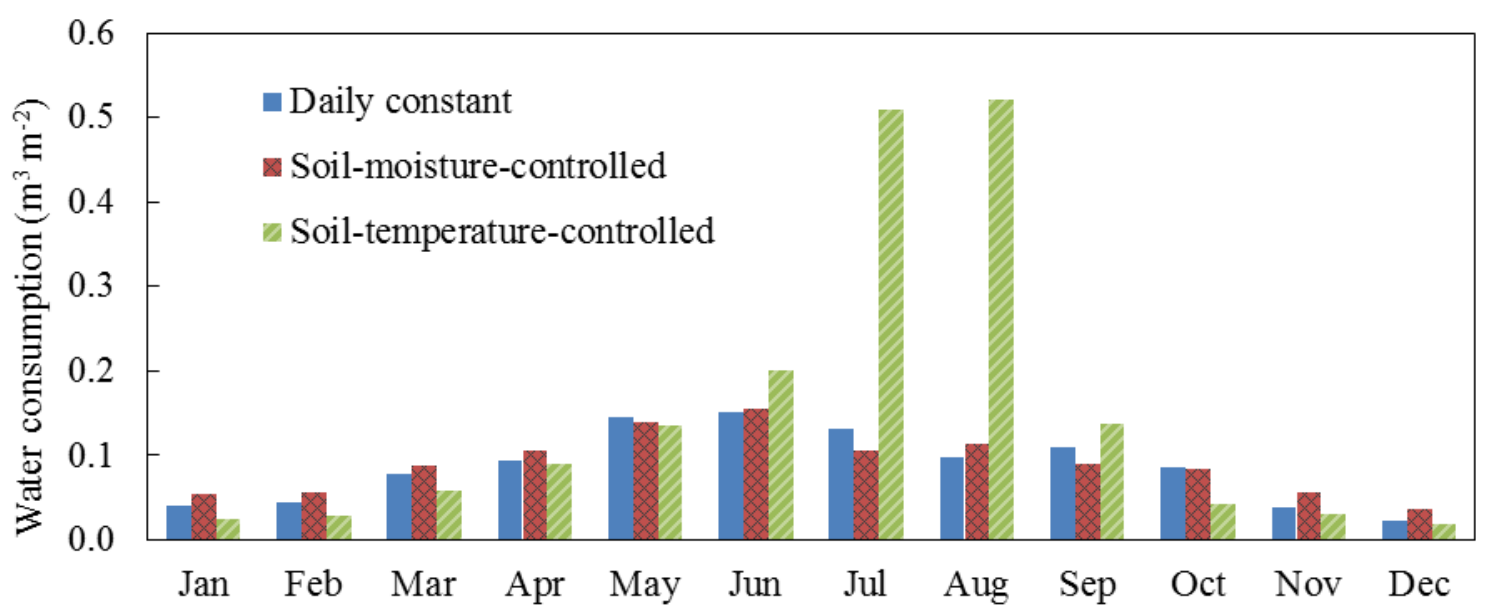

(b)

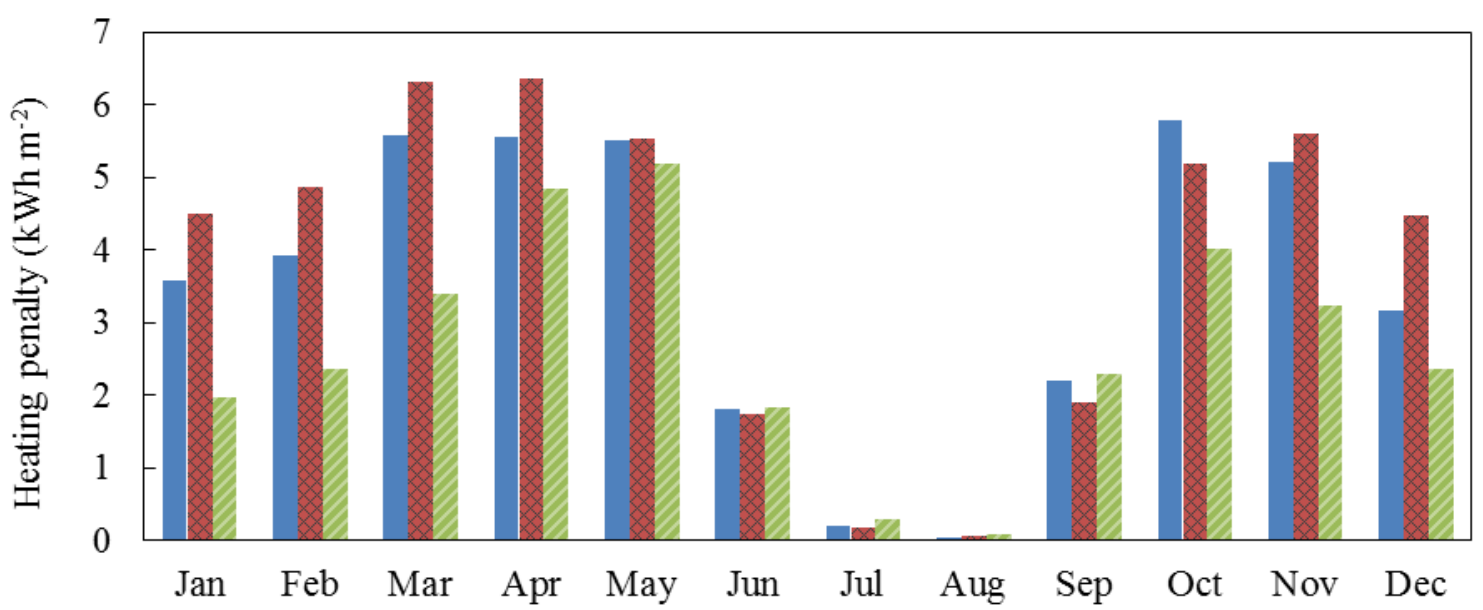

(c)

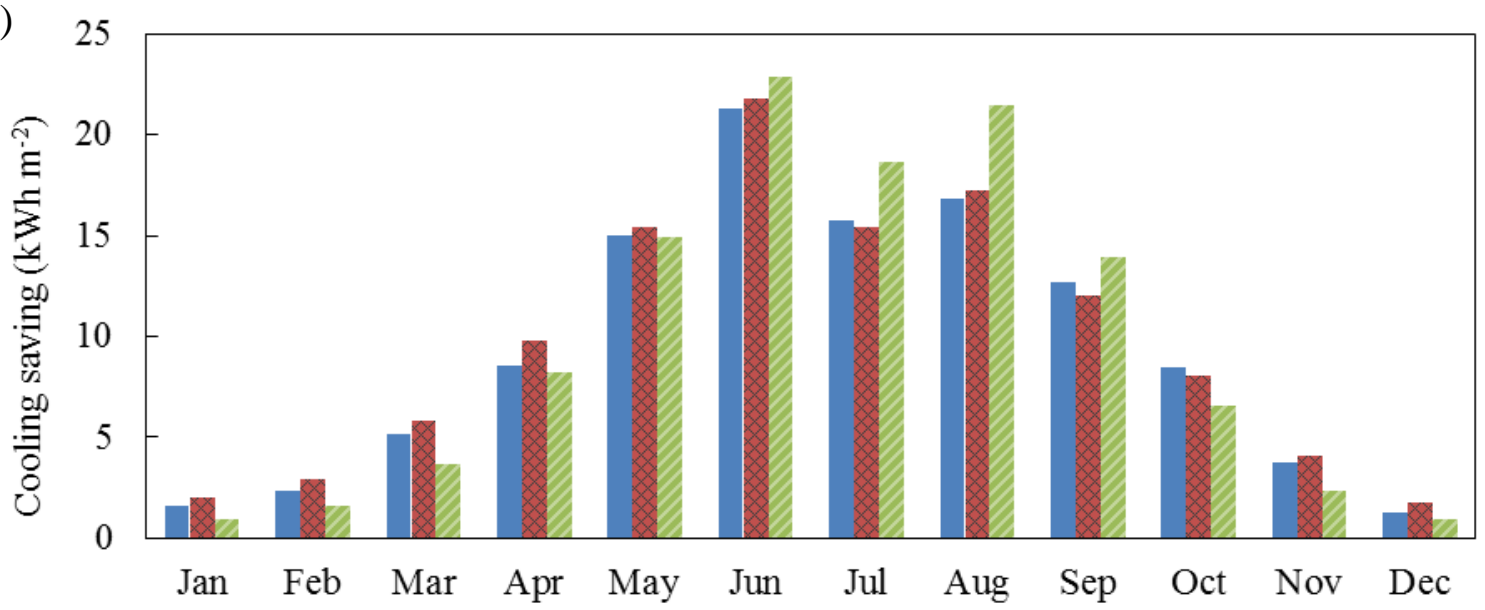

Fig. 5. Monthly (a) water consumption, (b) heating penalty, and (c) cooling saving by various irrigation schemes as compared to the no-irrigation case. 


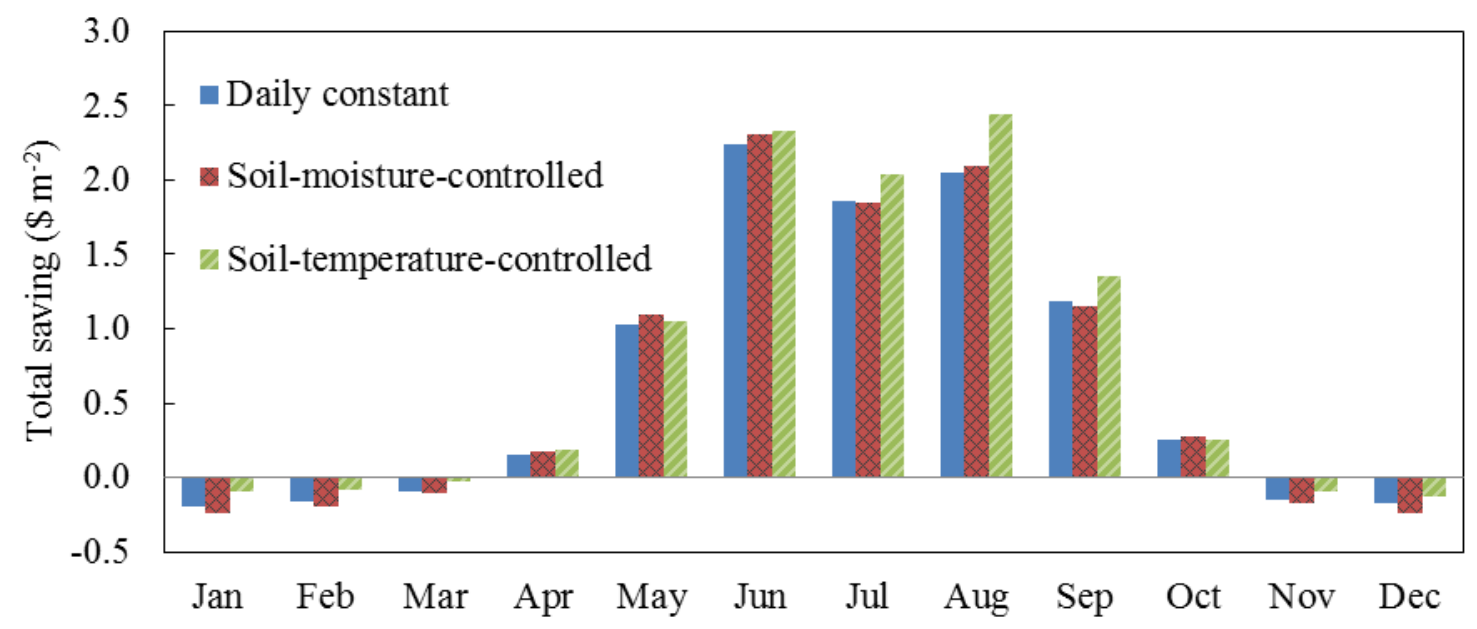

Fig. 6. Monthly total saving by various irrigation schemes as compared to the no-irrigation case. 


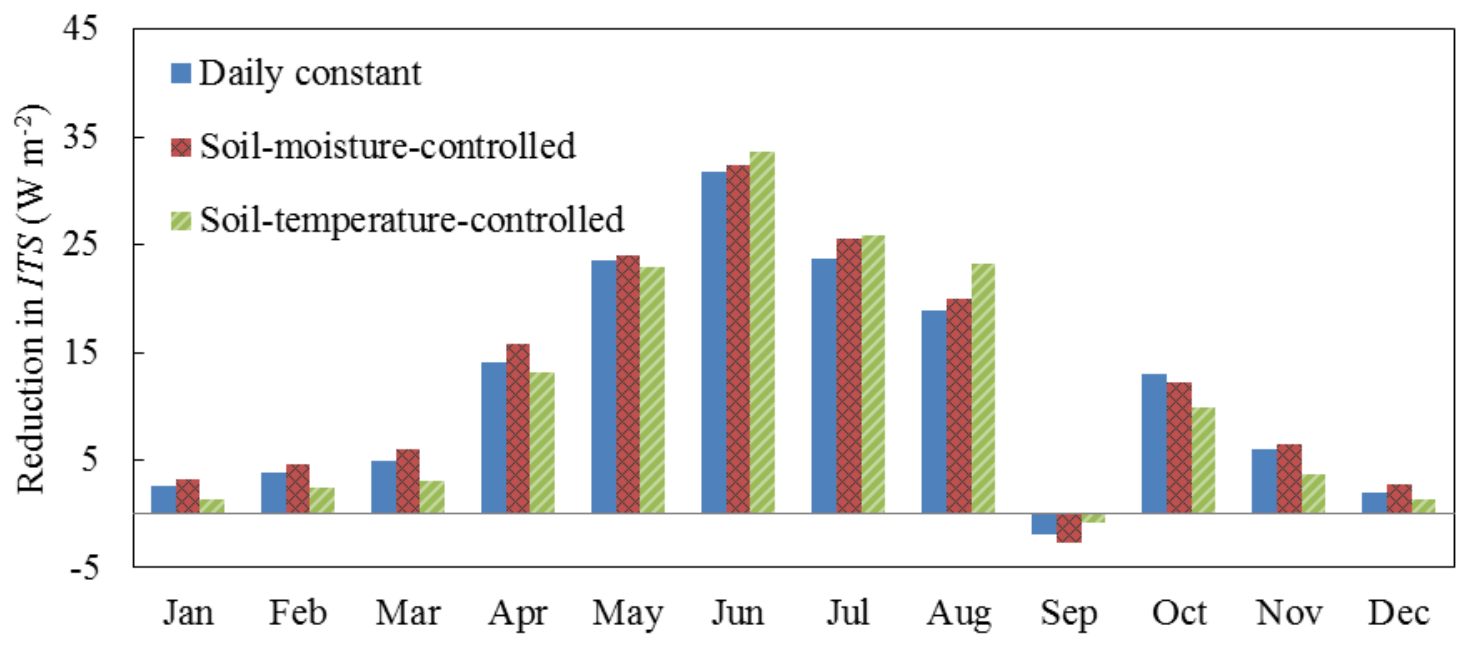

Fig. 7. Monthly reduction of ITS by various irrigation schemes as compared to the no-irrigation case. 


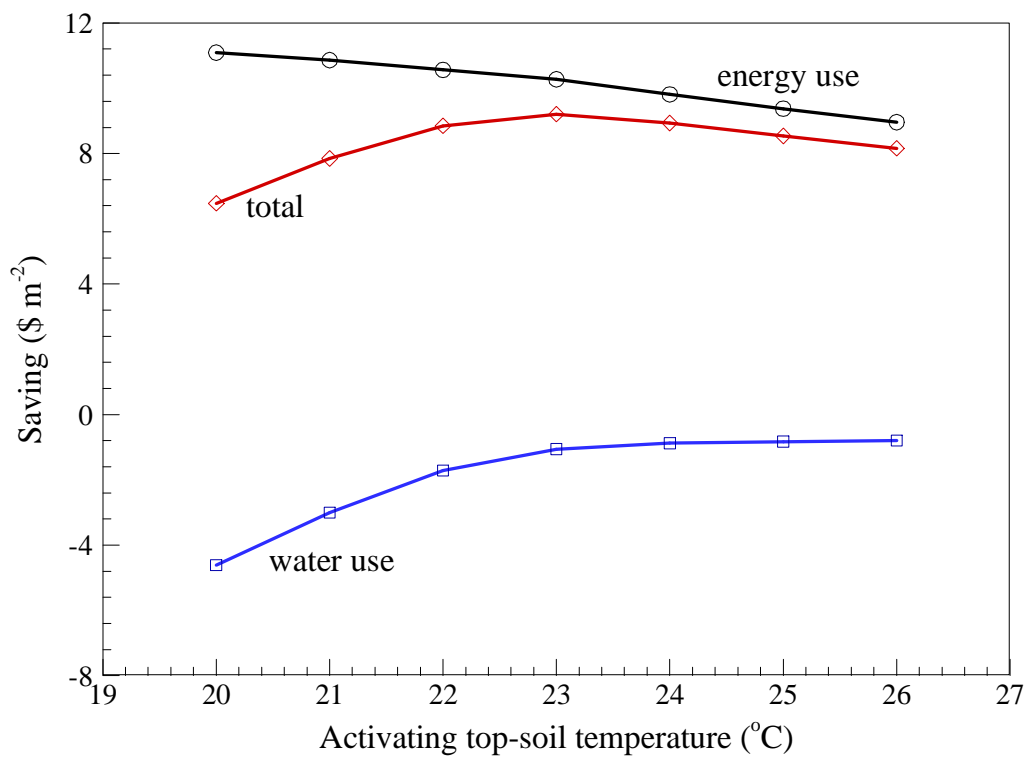

Fig. 8. Annual saving in cost of water consumption, energy cost and total cost by soiltemperature-controlled irrigation scheme with various activating soil temperatures as compared to the no-irrigation case. 
Table 1. Summary of electricity and water prices in Phoenix.

\begin{tabular}{lcc}
\hline Month & $\begin{array}{c}\text { Electricity price } \\
\left(\square \mathrm{kWh}^{-1}\right)\end{array}$ & $\begin{array}{c}\text { Water price } \\
\left(\$ \mathrm{~m}^{-3}\right)\end{array}$ \\
\hline January & 8.03 & 1.00 \\
February & 8.03 & 1.00 \\
March & 8.03 & 1.00 \\
April & 8.03 & 1.19 \\
May & 12.31 & 1.19 \\
June & 12.31 & 1.32 \\
July & 12.83 & 1.32 \\
August & 12.83 & 1.32 \\
September & 12.31 & 1.32 \\
October & 12.31 & 1.19 \\
November & 8.03 & 1.19 \\
December & 8.03 & 1.00 \\
\hline
\end{tabular}


Table 2. Summary of annual water usage, energy consumption, and total cost of all study irrigation schemes.

\begin{tabular}{lcccc}
\hline & $\begin{array}{c}\text { No- } \\
\text { irrigation }\end{array}$ & $\begin{array}{c}\text { Daily } \\
\text { constant }\end{array}$ & $\begin{array}{c}\text { Soil-moisture- } \\
\text { controlled }\end{array}$ & $\begin{array}{c}\text { Soil-temperature- } \\
\text { controlled }\end{array}$ \\
\hline Water usage $\left(\mathrm{m}^{3} \mathrm{~m}^{-2}\right)$ & 0 & 1.04 & 1.09 & 1.79 \\
Energy consumption $\left(\mathrm{kWh} \mathrm{m}^{-2}\right)$ & 1405.8 & 1335.7 & 1336.3 & 1321.6 \\
Annual total cost $\left(\$ \mathrm{~m}^{-2}\right)$ & 151.29 & 143.28 & 143.32 & 142.44 \\
\hline
\end{tabular}


Table 3. Summary of monthly averaged ITS of all study irrigation schemes.

\begin{tabular}{lcccc}
\hline \multirow{2}{*}{ Month } & \multicolumn{4}{c}{$I T S\left(\mathrm{~W} \mathrm{~m}^{-2}\right)$} \\
\cline { 2 - 5 } & No-irrigation & Daily constant & Soil-moisture-controlled & Soil-temperature-controlled \\
\hline January & 172.2 & 169.6 & 168.9 & 170.7 \\
February & 237.7 & 233.8 & 233.0 & 235.2 \\
March & 338.4 & 333.5 & 332.3 & 335.2 \\
April & 452.8 & 438.7 & 436.9 & 439.6 \\
May & 578.0 & 554.4 & 553.9 & 555.1 \\
June & 658.9 & 627.1 & 626.4 & 625.3 \\
July & 628.8 & 605.2 & 603.2 & 602.9 \\
August & 614.0 & 595.2 & 594.0 & 590.7 \\
September & 531.5 & 533.4 & 534.1 & 529.1 \\
October & 358.6 & 345.7 & 346.4 & 348.7 \\
November & 235.5 & 229.5 & 229.0 & 231.8 \\
December & 151.7 & 149.8 & 149.0 & 150.3 \\
\hline
\end{tabular}

